\title{
Em nome do Laico, do Cisma, da Liberdade Religiosa, amém
}

\author{
In the name of Laïque, Schism and Religious Freedom, Amen
}

\section{Bruno Curtis Weber ${ }^{\mathrm{a}} \odot$}

Resumo Este artigo trata de como a liberdade religiosa é apresentada no legislativo federal brasileiro, e está estruturado da seguinte maneira: primeiro, apresenta-se uma breve discussão conceitual sobre as categorias secularização e laicidade, compreendendo que ambas categorias se referem ao deslocamento do religioso na modernidade, mas traduzem movimentos distintos: secularização remete à "separação" entre Estado e religião, enquanto laicidade à participação das diversas perspectivas religiosas no espaço público - inclusive a ateia. Laicidade tornou-se um princípio constitucional através do instituto da liberdade de crença. Na sequência, é apresentada a análise qualitativa de 72 propostas de lei em tramitação no Congresso Nacional brasileiro que propõem regulamentar a pauta da liberdade religiosa. Conclui-se que tanto a separação entre Estado e religião quanto a participação religiosa no espaço público são acionadas pelos representantes eleitos em nome da liberdade de crença, porém especificamente sob o prisma axiológico cristão. Dessa forma, o pluralismo religioso, fundamental para a construção da laicidade e das liberdades religiosas, vem sendo posto em questão pela própria prática legislativa.

Palavras-chave Secularização. Laicidade. Liberdade religiosa. Congresso Nacional.

Abstract This paper discusses how religious freedom is being presented at the Brazilian Parliament. First, a short conceptual discussion on secularization and laicite is presented, assuming that both categories refer to religious transformations in modernity, although with different meanings: whereas secularization regards a "schism" between State and religion, laicité refers to multiples religious participation perspectives on public sphere - atheist included. The latter has become a constitutional principle through the institution of freedom of believe. Second, a qualitative analysis of 72 draft bills on religious freedom issues in course on the Brazilian National Congress is presented. Data suggests that both categories - the separation between State and religion, and religious participation on public sphere - are set by representatives in the name of freedom of believe, but specifically on christian axiological perspective.

a Doutorando do Programa de Pós Graduação em Ciências Sociais da Universidade Federal do Espírito Santo (UFES). E-mail: bcurtisweber@msn.com 
Therefore, religious pluralism, a fundamental principle to constructing laicité and religious freedom, has been put into question by legislative practice.

Keywords Secularization. Laicité. Religious freedom. Brazilian National Congress.

\section{INTRODUÇÃo}

A liberdade religiosa é um tema controverso, apesar de ser considerada uma cláusula pétrea da Constituição brasileira, evidente pela dificuldade de se precisar sua forma e seus limites sem recorrer a definições por demais abstratas para qualquer aplicabilidade. Nesse sentido vão as colocações do jurista Fábio Carvalho Leite: ele defende que é preciso que se elabore uma legislação que dê uniformidade às decisões jurídicas acerca do tema (LeITE, 2014, p. 451). No intuito de analisar o tratamento que a pauta vem recebendo na atualidade, o presente artigo se propõe a seguir o tom impresso por Giumbelli e Scola de “(...) deslocar a discussão, situando-a não tanto - ou não somente - no plano de definições jurídicas de primeira ordem, e sim no plano em que se especificam princípios constitucionais, como é o caso da liberdade religiosa" (Giumbelli; Scola, 2016, p. 27).

Nesta senda, reconhecemos que o dispositivo constitucional, contido no art. $5^{\circ}$, inciso VI, vem ganhando crescente atenção dos legisladores brasileiros. Isso se manifesta pelo levantamento aqui realizado, em que percebemos uma multiplicação do número de proposituras aderentes aos termos "liberdade religiosa" em pesquisa feita nos sítios eletrônicos do Congresso Nacional, quando comparado com a legislatura anterior.

Neste levantamento, realizamos uma leitura panorâmica e conteudística dos Projetos de Lei (PL) que tangenciam o tema. Nesse exercício, percebemos uma espécie de "regra" entre as motivações das proposições. Sob o manto generalista da "liberdade de consciência e de crença", preconizadas no art. $5^{\circ}$, identificamos um padrão que se delineia ora mais, ora menos explicitamente de acordo com os valores especificamente cristãos dentro das justificativas apresentadas pelos parlamentares na fundamentação de seus PLs. O material indica que o preceito da liberdade religiosa vem sendo encampado por parlamentares para defenderem posições e interesses específicos do recorte cristão do religioso: fundamenta-se no gênero constitucional (liberdade das religiões) para se defender a espécie axiológica cristã.

É importante, antes, fazermos uma breve confrontação entre as noções de secularização e laicidade. Consideramos que a análise desses conceitos nos auxiliará a compreender o tratamento que a pauta da liberdade religiosa vem tendo na vida política brasileira. Secularização remete ao cisma entre religião e sociedade 
(GiumbelLI, 2016, p. 21; Bossio, 2018, p. 151), enquanto laicidade reclama a integração dos discursos religiosos diversos para a construção da esfera pública (BlanCARTE, 2006), bem como a equidistância do Estado com relação a credos específicos (LEITE, 2014, p. 326). A partir dos levantamentos feitos nos sites do Congresso Nacional verificamos que tanto o discurso da separação quanto o discurso da participação são invocados pelo prisma axiológico cristão, o que fica explícito nas justificativas apresentadas para as proposições legislativas. Portanto, as "liberdades das religiões" de outras matrizes são ignoradas, tratadas como meros apêndices aos argumentos dos PLs, ou ainda tratadas como ameaça à continuidade nômica cristã.

Daremos seguimento pela apresentação de nossos referenciais teóricos. Em um segundo momento, faremos uma breve nota metodológica para, em seguida, apresentarmos, de forma crítica, nossos achados. Na conclusão, traremos a contribuição propriamente sociológica do presente trabalho, que reside na análise dos valores defendidos pelos legisladores enquanto delegados legitimados pela própria sociedade para conformarem a sua representação.

\section{ENTRE 0 CISMA E A INCLUSÃO: LIBERDADE(S) RELIGIOSA(S) COMO PAUTA}

Para balizar a compreensão dos materiais apresentados, é importante construir alguns acordos conceituais que tangem o tema da liberdade religiosa. Secularização e laicidade são termos de longa carreira na Sociologia da Religião, não sendo o escopo deste artigo realizar uma exegese de suas variações. Quando muito, visamos deixar claro o posicionamento que será assumido enquanto ferramental para a análise do material.

Primeiramente, é importante levar em conta que o termo laicidade tem uma origem e um uso estritamente latinos (DACosta, 2017; BAuBÉrot, 2011; BlanCARTE, 2006; CAETANo, 2006). Isso significa que as publicações germânicas - incluindo aí as anglófonas - ignoram o possível lapso semântico, abdicando-se mesmo do emprego do termo "laicidade" ou algum correlato, tratando "secularização" (secularization, Säkularisierung etc.) como ferramental suficiente para se compreender a relação entre religião e as outras esferas do mundo social. Na melhor das hipóteses, laicité é tratada como um movimento pontual ligado a uma inspiração jacobinista, meramente como um case histórico francês da dita "secularization" (e.g. GunN, 2004). O fato é que tais autores moldaram a episteme sociológica da subárea e, por consequência, os programas de pesquisa internacionalmente, por mais de um século.

Evidentemente, esses são termos imbricados, já que ambos remetem ao deslocamento do religioso na modernidade. Contudo, é necessário remarcar as 
distinções conceituais, até porque no contexto latino-americano o Estado laico "se converte numa clara necessidade como instrumento político e jurídico para proteger os direitos de minorias” (Blancarte apud Bossio, 2018, p. 151).

Nessa linha, o conceito de laicidade suporta a dimensão da pluralidade, considerando a participação isonômica dos diversos discursos, religiosos ou não, na construção das deliberações. Portanto, o Estado laico não adotaria uma preferência religiosa em detrimento de outras posições, mas também não se assumiria enquanto "Estado ateu" (LEITE, 2014, p. 326), no qual todas as religiões são excluídas da formação institucional. A definição do Estado laico não passaria tanto pelo "separar", enfim, mas mais pelo "abarcar" (cf. BlANCARTE, 2015, p. 670-671), enquanto secularização residiria num "abandono, redução, subtração do status religioso" e ainda "defecção, uma perda para a religião, e emancipação com relação a ela" (FoERSTER, 2007, p. 204). Não por acaso, obras crítico-compilatórias, como Les Théories de la Secularisation (Tschannen, 1992) e Public Religions in Modern World (CASANOVA, 1994), veem a diferenciação como uma característica definidora do paradigma da secularização ${ }^{1}$.

Feita essa pontuação, e seguindo a linha de Blancarte, percebemos que não há contradição em afirmar que existem experiências históricas que por vezes se aproximam do modelo secular, ao mesmo tempo em que se afastam do modelo de laicidade, e vice-versa. O Uruguai, por exemplo - país que tem na noção de laicidade um objeto de identidade nacional (DACostA, 2011) -, não conta com figuras jurídicas ou procedimentos específicos para coletivos religiosos, e também não apresenta um aparato estatal especializado para registro desses mesmos coletivos (GiumbelLi, 2016, p. 22). Isto é, apesar de sua estrutura tipicamente secular e de sua postura histórica de afastar as religiões das participações públicas, não seria correto, conceitualmente, enquadrar aquela sociedade no modelo de laicidade. Até porque, conforme demonstram Gerardo Caetano (2013) e Néstor Da Costa (2017), a identidade nacional uruguaia requer que os indivíduos abdiquem das identidades pessoais atreladas às suas respectivas religiosidades em nome de uma "cidadania hiperintegradora", que exige a subsunção das individualidades. "O ânimo hiperintegrador, negador das diferenças, disciplinador e centralizador no Estado tem sido a principal matriz da sociedade uruguaia” (DACosTA, 2017, p. 83, tradução livre).

1 A diferenciação pode ser entendida tanto em sua perspectiva funcionalista, como define a visão sistêmica - "a religião torna-se um subsistema dentre outros subsistemas", perdendo sua centralidade (DOBBELAERE, 2002, p. 19); como num sentido mais diretamente weberiano, como emancipação da ordem jurídico-política com relação à religião (MARIANO, 2011, p. 245). 
Quando muito, o Uruguai se definiria como uma sociedade "laicista", o que é bastante diferente de uma sociedade "laica", pois, conforme Roberto Blancarte,

O laicismo, ligado ao [conceito] anterior [o de laicidade] é sobretudo uma atitude proselitista de combate (como todos os ismos) em favor da causa da laicidade. O problema surge porque o emprego de ambos termos é por vezes arbitrário e indistinto, o que gera erros de apreciação e de interpretação acerca de nossa história ou vida social. Em boa medida, as razões desta confusão se originam no fato de que a laicidade, defendida pelo laicismo, adquiriu um caráter combativo e anticlerical em particular nos países de tradição latina, aproximadamente entre 1850 e 1950 (BLANCARTE, 2011, p. 183-184, tradução livre).

Alega-se que a postura laicista - assumida por algumas nações - advém de certa interpretação da chamada Lei da Separação, promulgada na França em 1905 e considerada como um marco simbólico da concretização da autonomia do Estado com relação às religiões. No entanto, essa interpretação específica ignora os complexos debates que foram desenvolvidos até a promulgação do ato. É preciso recordar que, na mesa de negociação daquele texto, não havia consenso sobre os dispositivos da lei, mas uma matizada heterogeneidade de posicionamentos tanto entre os "laicistas" - dos mais radicais aos mais diplomáticos - quanto entre os "clericalistas" (ВАUВÉROT, 2011, p. 64). O resultado foi a promulgação do ato com uma série de concessões de ambas partes, como a supressão de artigos originalmente pautados (Ibid.) e o compromisso, pelo Estado, de subsidiar a construção de 450 templos católicos, além de prover pela manutenção de tantos outros ao longo dos anos subsequentes (Oro, 2015, p. 58).

Outra importante ressalva é que a Lei da Separação não goza da originalidade que o mundo atribui à França. O México já havia publicado uma "Lei da Separação" em 1861, aperfeiçoada em 1874, que serviu largamente de referência para a construção da lei francesa (BAUBÉROT, 2007, p. 120). O relator da comissão parlamentar de 1905 concluíra que, através da lei mexicana, o país americano "realmente conhece a paz religiosa" (Ibid.). Na verdade, a comissão pautou suas discussões a partir de estudos feitos sobre legislações já existentes nas Américas, como - além do próprio México - o Canadá, os Estados Unidos e até o Brasil (Ibid.), que através do Decreto $\mathrm{n}^{\mathrm{O}}$ 119-A de 1890 consagrava a plena liberdade dos cultos e extinguia o padroado.

Esses estudos que embasaram a Lei da Separação francesa passaram a compor um documento chamado "Relatórios Briand", que contém todo o histórico das 
deliberações então realizadas. O curioso é que, em 2005, a Assemblée Nationel patrocinou uma reedição dos Relatórios Briand, como forma de comemoração do centenário da Lei da Separação. Contudo, na reedição foi omitido justamente o capítulo "Législations Étrangères", onde constavam os estudos que inspiraram a versão francesa da laicidade (BАUвÉROT, 2007, p. 121). Essa omissão talvez tenha autorizado o Alto Conselho da Assembleia francesa a justificar seu orgulho ao afirmar publicamente que a lei de 1905 "se tornou objeto de encanto para todo o mundo" e que "suscitou cópias e fez nascer imitações" (BАUвÉrot, 2007, p. 120). A questão é que práticas abertamente laicistas se basearam numa interpretação peculiar da experiência francesa, uma vez que essa ignora tanto as concessões que precisaram ser feitas para que a Lei da Separação se tornasse viável quanto as inspirações e motivações de origem diversa daquela imaginada originalidade europeia.

Como caso emblemático temos a Turquia, que, através de Mustafá "Atatürk" Kemal, deliberadamente se inspirou e radicalizou o modelo da lei francesa quando, nas décadas de 1920 e 30, desautorizou a manifestação de qualquer pertença religiosa em espaço público, além da extinção do califado e de suas representações (TAHIRLI, 2005), medidas que não privilegiam a laicidade, apesar de serem abertamente laicistas. No mesmo mote, as justificativas para a "hiperintegração" uruguaia, expressa legalmente pela primeira vez na Constituição de 1919, também se baseia nesse tipo de interpretação do processo francês (DACostA, 2017, p. 74). Somente no século XXI o país passou a assumir a discussão de "um modelo de laicidade que não suponha a exclusão da diversidade religiosa, mas sim que a integre socialmente", ainda que haja forte resistência para tanto (CAETANo, 2013, p. 131).

Nesses termos, concordamos com Antônio Flávio Pierucci que "a secularização que importa em primeiro lugar [...] é a secularização do Estado como ordem jurídica" (PIERUCCI, 2012, p. 90, grifo no original). Ou seja, é imprescindível apreendermos a autonomia da ordem jurídico-política com relação às formas, à axiologia e aos símbolos religiosos. Essa autonomia, no limite, protege as diversidades (incluído aí o posicionamento ateu) da submissão a um Estado teocrático ${ }^{2}$ - apesar de, por outro lado, não proteger os crentes de qualquer fé contra um Estado

2 Esse limite é útil apenas como uma referência teórica, pois Alfred Stepan, em The multiple secularism of modern democratic and non-democratic regimes, traz-nos as leituras que a Índia, Senegal e Indonésia fizeram da secularização, desenvolvendo políticas muito mais inclusivas com relação às minorias religiosas do que a própria França ou mesmo os Estados Unidos. A Indonésia, aliás, lançou mão da doutrina chamada Pancalisa como política de Estado na década de 1940, política de fundamentos muçulmanos que tem entre seus princípios a "democracia mediante consulta e consenso" e a "justiça social" (STEPAN, 2011, p. 28). 
positivamente ateu, como o foi a União Soviética. Por isso mesmo, é importante recuperarmos a noção de um Estado laico "equidistante em relação a credos específicos, que melhor permite o respeito não 'à religião', mas 'às religiões' indistintamente" (LeITE, 2014, p. 326), para nos utilizarmos uma vez mais da metáfora geométrica de Fábio Leite.

A essa equidistância arbitral do Estado com relação aos credos deve ser somada uma dimensão positiva, aquilo que Susana Andrade chamou de "laicidade inclusiva" (ANDRADE, 2009), ou seja: a institucionalização de espaços que ensejem a participação de diversas vozes religiosas na conformação da esfera pública. Isso ressoa com Blancarte, para quem essa dimensão é fundamental para a atuação das minorias no contexto latino-americano, e para Néstor Da Costa, que identifica que, atualmente, "o termo laicidade parece estar mais focado nas formas concretas de convivência e da relação entre Estado e as confissões religiosas" (DACosTA, 2017, p. 84).

Em resumo: i) o cisma estrutural - a diferenciação - livra a ordem jurídico-política de um compromisso confessional; tal separação entre o religioso e as estruturas que normatizam a sociedade é a característica de uma sociedade secular; ii) é preciso reconhecer que na composição dessa mesma estrutura política diferenciada devem ser absorvidas as demandas de origens religiosas diversas - estamos considerando que a estrutura jurídica responde aos fatos concretos a partir das lentes designadas pelas leis, que são politicamente estabelecidas, e que esse é o princípio de um Estado laico; iii) os posicionamentos e demandas político-religiosas têm pesos distintos entre si quando postos à mesa do Estado, pesos estes que são historicamente atribuídos.

O argumento do presente texto é que os posicionamentos e demandas político-religiosas apresentadas no nosso Congresso vêm usando da bandeira do Estado laico para reafirmar, preponderar, inaugurar ou recuperar - mais ou menos explicitamente - normas fundadas em valores especificamente cristãos, o que põe em questão a própria concepção de laicidade.

\section{BREVE NOTA METODOLÓGICA}

Para este artigo, o levantamento de projetos de lei foi realizado nos sites do Senado e da Câmara federais ${ }^{3}$, utilizando os termos "liberdade religiosa", "organização religiosa” e “organizações religiosas” entre aspas para pesquisa dos termos

3 Disponíveis, respectivamente, em < https://www25.senado.leg.br/web/atividade > e < https://www. camara.leg.br/busca-portal/proposicoes/pesquisa-simplificada>. Último acesso: 23/05/2021. 
precisos. Recorremos a três filtros: Projetos de Leis (PL); Projeto de Lei Complementar (PLP); e Proposta de Emenda à Constituição (PEC). Somente proposições em tramitação foram catalogadas, independentemente da data de sua proposição, prescindindo-se tanto das já arquivadas, quanto das já transformadas em normas jurídicas. Essa escolha foi feita no intuito de oferecer um horizonte de perspectivas para o médio prazo, bem como qualificar a evolução do interesse do Congresso na regulamentação do tema proposto.

Foram catalogados 66 PLs da Câmara e 2 PLs do Senado, 3 PLPs oriundos da Câmara, e uma PEC, também da Câmara dos Deputados. Optamos por fazer levantamentos com menos filtros e termos de busca, uma vez que não nos ativemos somente aos conteúdos das proposições. Todas as propostas foram fichadas, bem como suas respectivas justificações - as quais consistem em anexos nos quais o proponente destila seus arrazoados quanto à relevância e à pertinência da minuta apresentada. Além disso, acompanhamos os votos e os pareceres, quando o houveram, feitos aos projetos. Cremos que assim poderíamos nos aproximar de maneira mais fidedigna do "espírito" de cada uma das minutas, além de nos propiciar a realização de uma análise geral mais adequada dos valores que circulam nas casas legislativas acerca do tema.

É preciso levar em conta que caso um projeto recente seja similar ou tenha conteúdo parecido com outro que já tramitava anteriormente, o mais recente é anexado ao mais antigo e eles são repassados conjuntamente a um relator designado, que lavrará seu parecer. O relator poderá deliberar separadamente ou propor um Projeto Substitutivo de Lei (ou simplesmente Substitutivo), unificando as propostas apensadas. Ainda que exista esse protocolo, realizamos a análise em separado das justificações e dos conteúdos apresentados em cada uma das proposituras que eventualmente estavam tramitando em conjunto. Até porque existe a possibilidade de a relatoria desanexar as minutas e apenas uma delas vir a se tornar norma jurídica. Por conta desse protocolo, ao longo dos levantamentos foram incluídas à análise minutas que porventura compunham a árvore de anexos e que não continham os termos escolhidos para a realização da busca. Quando imprescindível, tais minutas foram incorporadas ao corpo de análise. Outra observação de cunho mais técnico é que, ao cabo de cada legislatura, todas as propostas que ainda não foram votadas em plenário são arquivadas. Existe a possibilidade de desarquivamento da proposta mediante requerimento simples, feito pelo autor da proposta até o sexto mês da legislatura seguinte. Por isso, por vezes, um mesmo PL conta com mais de um relatório, já que cada desarquivamento percorre todas as etapas do rito novamente. 
Apesar de ter sido um levantamento exaustivo de todas as proposições existentes sobre o tema dentro dos filtros mencionados, suplementadas pelos casos citados no parágrafo acima, a análise se restringirá ao aspecto qualitativo. Como não seria possível a apresentação de todos os documentos encontrados, para a apresentação dos dados elegemos justificações e PLs considerados típicos dentro de cada pauta. Com essa estratégia pretendemos ilustrar argumentos e posicionamentos que se repetem com certa frequência, ao mesmo tempo em que procuramos abranger o maior número de pautas possível.

\section{SÍNTESE DOS LEVANTAMENTOS}

O PL n ${ }^{0} 6314 / 2005$ foi apresentado em dezembro de 2005 pelo pastor assembleiano Hidekazu Takayama, que exerceu quatro mandatos consecutivos, atuando na Câmara entre os anos de 2003 e 2018 por diversos partidos (PR, PTB, PMDB e, por fim, PSC). A proposição acrescenta um inciso ao art. $142^{\circ}$ do Código Penal, que versa sobre possibilidades de exclusão dos crimes de injúria ou difamação. Atualmente, são três os casos possíveis de indulto: i) quando a ofensa édita em juízo pela parte interessada ou por seu procurador; ii) quando se trata de uma opinião desfavorável no âmbito da crítica literária, artística ou científica; ou iii) quando um funcionário público emite um conceito desfavorável, que ele preste no cumprimento do seu ofício. Takayama propõe um quarto caso possível: "IV - a opinião de professor ou ministro religioso no exercício do magistério ou de seu ministério"4. Na justificativa de Takayama, é defendido que deve-se permitir ao educando "a análise crítica dos acontecimentos e da história”, e, por seu turno, o Ministro religioso "segundo os valores de sua fé tem que se posicionar contra determinadas condutas que afrontam esses valores, e que podem ser considerados como ofensivos por outros que defendem posição divergente”.

Alguns aspectos devem ser atentados acerca do PL. Primeiro que é um dos projetos mais antigos em tramitação ${ }^{5}$ dentre os que abordam o tema liberdade religiosa. Segundo que, apesar de sucinto, o dispositivo é bastante complexo, porque modifica o Código Penal ${ }^{6}$. Além disso, devido à sua abrangência, 14 PLs estão

4 Disponível em <https://www.camara.leg.br/proposicoesWeb/fichadetramitacao?idProposic ao=308517> Último acesso: 23/05/2021.

5 Antecedem-no os PLs 7001/2002 e 7030/2002, o primeiro impedindo a realização de vestibulares, o segundo de Concursos Públicos aos sábados, dia "santificado", segundo expressão do proponente Dr. Evilásio (PSB), de diversas religiões existentes no Brasil.

6 Tanto que foi necessária a criação de uma Comissão Especial em 2015 para a análise da proposição e seus anexos, que deveria contar, para julgamento de mérito e juridicidade, com membros adicionais das Comissões Permanentes de Educação, de Direitos Humanos e Minorias, e também da Comissão de Segurança Pública e Combate ao Crime Organizado. 
apensados à proposta. Daí um terceiro ponto chama a atenção: ao longo da $52^{\mathrm{a}}$ Legislatura (2003-2006) e da $53^{\mathrm{a}}$ (2007-2010) nenhuma proposição foi anexada ao PL, significando que não houve interesse em nenhuma das duas legislaturas em regulamentar a matéria. Aliás, o PL 6314/2005 recebeu um parecer desfavorável do relator Luiz Couto (PT) em 2006, quando escolhido para analisar a proposta em nome da Comissão de Constituição e Justiça e de Cidadania (doravante CCJC):

A exceção que se pretende criar esbarra no princípio da igualdade de tratamento em relação a outras categorias de profissionais, que não se encontram igualmente amparados pela hipótese do crime de injúria ou difamação [...]. Assim, a nosso ver, contemplar tais profissionais revela-se inconstitucional e injurídico, na medida em que se cria um privilégio legal não estendido a outras pessoas que desempenham tarefas semelhantes ou afins. No mérito, não merece prosperar o Projeto, uma vez que a exclusão do crime na hipótese pretendida em nada aperfeiçoa o ordenamento jurídico brasileiro. Ao contrário, milita em prejuízo da vítima da injúria e da difamação, que se vê impotente e desprotegida diante de ataques sofridos, sem poder se defender dos seus agressores (BRASIL, 2006, p. 2, grifos nossos).

O parecer não foi votado nos anos seguintes até que em 2012 (portanto na $54^{\mathrm{a}}$ Legislatura - 2011-2014) o projeto de Takayama recebeu seu primeiro PL apensado. O Professor Victório Galli (à época do PMDB, posteriormente PSL e depois PSC), por meio do PL 4500/2012, inseriu um inciso no mesmo dispositivo do Código Penal, sugerindo exclusão de crime de injúria e difamação no caso de: "IV - a manifestação de crença religiosa, em qualquer modalidade, acerca da sexualidade”. Na justificativa de Galli aparecem alguns elementos que vão se repetir ao longo de diversas outras proposituras até os dias de hoje; são elas:

1) a menção aos incisos IV (referenteà liberdade de pensamento) e VI (da liberdade de consciência e de crença, sendo assegurado o livre exercício dos cultos), inscritos no art. $5^{\mathrm{o}}$ da Constituição;

2) menção ao inciso I do artigo $19^{\circ}$ da Carta, que veda aos três entes do Estado de interferirem no funcionamento de cultos religiosos e igrejas;

3) uma "indevida interferência do Poder Público" na atividade das igrejas;

4) e, como mais sutil e interessante pontuação: apesar de iniciar o argumento a partir do princípio da liberdade religiosa - donde se depreende que deveriam ser abrangidas as liberdades religiosas -, o texto remete a cons- 
truções frasais, elementos e símbolos especificamente cristãos. Não se fala em "mesquitas", "terreiros", "sinagogas" ou mesmo no genérico "templo", mas em igrejas ou em texto sagrado. Posteriormente, termos semelhantes aparecerão em outros PLs.

Fato é que a apensação do PL 4500/12 ao projeto de 2005 engendrou uma nova remissão para a CCJC. Dessa vez, os dois PLs passaram a ser apreciados de forma conjunta, e a relatoria lavrou o seguinte parecer em maio de 2013:

A exceção que se pretende criar contém um vínculo direto com o princípio constitucional da liberdade de expressão e de pensamento [...]. Principalmente no caso de líderes religiosos, que, pela natureza de sua função religiosa, devem expressar as doutrinas e os dogmas de sua profissão de fé, não podendo permitir que estes sejam tolhidos na sua manifestação doutrinária, sob pena de violação do direito de culto [...] até mesmo para garantir a igualdade de tratamento em relação àqueles que, por ofício ou mister, tenham de emitir opiniões doutrinárias, de cunho científico ou religioso. No mérito, os projetos merecem prosperar, diante do que apresentamos substitutivo contemplando os textos de ambas as proposições (BrasIL, 2013, p. 2, grifos nossos).

Nada surpreenderia se parecer tão divergente daquele primeiro não tivesse vindo do mesmo Luiz Couto, tão assertivo ao apontar a injuridicidade e inconstitucionalidade da mesmíssima minuta sete anos antes.

Devemos também destacar o fato de que entre 2015 e 2020 ( $55^{\mathrm{a}}$ e $56^{\mathrm{a}}$ Legislaturas) outros 13 projetos foram apensados ao 6314/o5. Ou seja: se ao longo de sete anos a proposição de Takayama tramitou de forma avulsa, em 2020 ela se tornou a raiz de uma árvore de 14 anexos. O que, ao menos em números, é bastante positivo, uma vez que é ponto pacífico que o tema "liberdade de crença" deve ser regulamentado para orientar decisões jurídicas, dando-lhes maior segurança. Vemos com nitidez que as legislaturas mais recentes vêm se preocupando crescentemente com a pauta. Por exemplo: se adicionamos à busca as propostas já arquivadas no filtro disponibilizado pelo site da Câmara dos Deputados, temos um total de 98 propostas, entre PLs, PLPs e PECs. Cinquenta e cinco advêm das $55^{\mathrm{a}} \mathrm{e}$ $56^{\mathrm{a}}$ Legislaturas; as demais 43 distribuem-se ao longo das outras sete. Cabe ainda observar que 31 foram apresentadas nos dois primeiros anos da $56^{\mathrm{a}}$ Legislatura, ou seja, entre 2019 e 2020. 
Enquanto o PL 6134/o5 recebeu pareceres antitéticos de um mesmo relator dentro de sete anos, o PL 1804/2015 obteve dois votos louvando seu mérito por dois relatores distintos em apenas quatro. A proposição foi apresentada em junho de 2015 por Rogério Rosso (PSD) e prevê a ampliação da pena para quem escarnecer publicamente de alguém por motivo religioso. Originalmente o Código Penal prevê a detenção de um mês a um ano ou multa. A proposta de Rosso sugere que a previsão de pena passe a ser de quatro a oito anos de detenção $e$ multa. Isso porque:

A intenção desse projeto de lei é proteger a crença e objetos de cultos religiosos dos cidadãos brasileiros, pois o que vem ocorrendo nos últimos anos em manifestações, principalmente LGBTS, é o que podemos chamar de "Cristofobia", com a prática de atos obscenos contra católicos e evangélicos (BRASIL, 2015a, p. 2, grifo nosso).

Sua justificativa ainda endossa o argumento do sociólogo Valmor Bolan, de que a Parada Gay de 2011 insinuou "que o amor de Jesus seria também gay" e que "tudo isso pode se resumir numa palavra pouco mencionada hoje em dia, mas tratou-se de um sacrilégio" (Bolan apud Brasil, 2015a, p. 2). Os arrazoados levaram ao primeiro parecer favorável na CCJC, dado ainda em 2015 por Jefferson Campos (pastor da Igreja Quadrangular, vinculado ao PSD), que concorda que "não podemos tolerar que participantes de manifestações públicas, continuem a desrespeitar a fé cristã e os símbolos do cristianismo sem sofrer qualquer punição" (BRASIL, 2015b, p. 2).

Entre 2015 e 2019, o PL 1804/15 recebeu 13 anexos, com variações nos valores da previsão de pena. Dentre elas, três argumentos se destacam:

i) PL 8854/2017 (Givaldo Carimbão/PHS): o deputado, então presidente da Frente Parlamentar Mista Católica, propôs o aumento de previsão de pena para 12 a 30 anos e multa. Givaldo afirma que "a nova tipificação torna crime as inúmeras manifestações de 'Paradas LGBT' ou 'Paradas Gay' que zombam e desrespeitam a fé de cristãos". Além disso, "serão também enquadrados como crime as exposições de arte, para mim 'arte do satanás'

7 O termo foi cunhado pelo jurista estadunidense Joseph Weiller e se remete a um apagamento sofrido pelo cristianismo, marcadamente na Europa, a partir do Iluminismo. Frequentemente, é instrumentalizado por movimentos conservadores cristãos para se referirem ao que consideram perseguição, ato preconceituoso ou de coerção contra símbolos cristãos ou pessoas identificadas com essa fé (cf. VAlLEJO, 2009). 
que buscam apenas ofender a fé cristã e destruir as famílias” (BRASIL, 2017a, p. 2).

ii) PL 2544/2019 (Gilberto Abramo/REP): O pastor da Universal já anuncia na própria ementa do PL que "proíbe o vilipêndio a crenças relativas à religião cristã". Por isso prevê no art. $2^{\circ}$ do seu projeto que "entende-se como ofensa à religião cristã, a utilização de todo e qualquer objeto vinculado à religião ou a crença de forma desrespeitosa ao dogma desta" (BRASIL, 2019a, p. 1). O interessante neste caso é que Abramo inverte a lógica das demais proposições: enquanto as demais anunciam uma norma genérica e somente na justificação se entrevê as motivações cristãs, aqui a própria lei é explicitamente cristã, e a justificativa se assenta em argumentos acerca da "liberdade de culto", "liberdade religiosa" e também da Declaração de Direitos Humanos.

iii) PL 4152/2019 (Chris Tonietto/PSL): A advogada do Centro Cultural Católico Dom Bosco justifica seu PL por "trata[r]-se de medida que reforça a identidade religiosa de nosso povo, não apenas esmagadoramente cristão ainda nos dias de hoje, mas formado sob uma base moral, cultural, simbólica e afetiva católica. O cristianismo é a própria face do povo brasileiro" (BRASIL, 2019b, p. 1). Tonietto recorre ao argumento da identidade nacional enquanto identidade cristã, recurso igualmente utilizado em outras ocasiões. A autora continua:

[...] a Cristofobia que em outras nações já descamba em perseguição aberta e execução de todos os que professam a fé no Redentor do gênero humano, no Brasil torna-os alvos fáceis de um ativismo judicial cada vez mais latente [sic], que, sob o pretexto de assegurar a laicidade do Estado e impedir perseguições a minorias religiosas, deseja proibir todos os símbolos [...] da fé que fundou o Brasil. (BRASIL, 2019b, p. 2).

É certo que, dentre as 13 proposições anexadas ao PL 1804/15, três justificam a ampliação da previsão penal por conta do crescimento da intolerância religiosa contra religiões de matriz africana, ou seja, por sua posição minoritária simbólica e numericamente. São eles: PL 8941/17 (Orlando Silva/PCdoB); PL 9398/17 (Vincentinho/PT); e PL 5496/19 (Marcelo Calero/CID). Ocorre que, uma vez apensados, os projetos tramitam conjuntamente, cabendo ao relator tomar a decisão de: ou separá-los para que tramitem de maneira independente, ou aglutiná-los e sugerir um Substitutivo, e este sim é o que seguirá o rito de apreciação. O segundo 
caminho foi o tomado para a matriz do PL 1804/15, através do parecer do pastor assembleiano da Vitória em Cristo, Sóstenes Cavalcante (DEM). Em seu parecer os PLs que se justificavam pelo serviço às minorias foi subsumido ao argumento genérico de que "o mandamento constitucional é violado sempre que alguém zomba publicamente da fé ou função religiosa alheia”.

"Liberdade religiosa" é compreendida em diversos âmbitos e aspectos, no tratamento oferecido pelos parlamentares. Ele vem sendo lido, por exemplo, dentro do âmbito tributário: o PLP 21/2020 apresentado por Soraya Manato (PSL) busca regulamentar o $\$ 4^{\circ}$ do art. $150^{\circ}$ da Constituição, que versa sobre a vedação de instituir impostos sobre: a) templos de qualquer culto; e b) patrimônio, renda ou serviços de partidos políticos. A proposta de Manato propõe a isenção de impostos sobre patrimônio, rendas e serviços religiosos, o que de alguma forma estende o adjetivo religioso àquilo que seria benefício de partidos políticos segundo a atual regra constitucional. No mesmo sentido vai o PL 5200/19 da evangelizadora capixaba Lauriete (PL), justificando que a isenção de encargos cartoriais para a aquisição de imóveis por templos de qualquer culto favorecerá a "expansão de valores espirituais, valorizando o emprego da atividade missionária" (BRASIL, 2019c, p. 3). Lembramos que "missão" é uma forma específica de proselitismo cristão, apesar de o argumento apresentado assentar na isenção de emolumentos para a formação de "templos de qualquer culto".

A liberdade religiosa é trazida para o primeiro plano também a partir de outro aspecto, qual seja: a reivindicação pela não intervenção do Estado nos expedientes litúrgicos. Nesta senda encontramos o PL 885/19, do pastor da Quadrangular Paulo Bergston (PTB) - o mesmo que propõe a instituição do Dia Nacional do Combate à Cristofobia, no PL 4986/20. O 885/19 é sintomático em sua justificação, pois ali encontramos o argumento de que:

[...] há uma clara tentativa de parcela minoritária da sociedade brasileira de silenciar as opiniões emitidas por líderes religiosos, criminalizando discursos eventualmente por eles proferidos a respeito da sexualidade, aborto, eutanásia, prostituição dentre outros temas.(BRASIL, 2019d, p. 2).

Por esse prisma, a liberdade religiosa é também utilizada para não criminalizar campanhas políticas feitas dentro de templos, conforme o PLP 219/20 de Cezinha de Madureira (PSD), "as ideias religiosas têm legitimidade para participarem do debate político” (Brasil, 2020a, p. 3). Proibir o debate político dentro dos templos, 
conforme é o entendimento da legislação eleitoral atual ${ }^{8}$, seria um sintoma de abuso de poder do próprio Estado contra a liberdade religiosa.

É dentro da mesma chave da liberdade religiosa que o PL 4949/19 do pastor da Universal Otoni de Paula (REP) procura legitimar a proibição do acesso de pessoas a determinados espaços, devido às suas orientações sexuais. O PL propõe alterações à Lei no 7.716/1989 - que "define os crimes resultantes de preconceito de raça ou de cor" . Originalmente a Lei dita em seu art. $4^{\circ}$, simplesmente, que é crime "negar ou obstar emprego em empresa privada", devido à raça, cor ou aos parâmetros de orientação sexual advindos do julgamento da ADO 26 (vide nota de rodapé $n^{0}$ 6). Otoni propõe a alteração do caput para: "negar ou obstar emprego em empresa privada, ressalvadas aquelas fundadas na liberdade de consciência e de crença, aqui incluído o livre exercício dos cultos religiosos" (BRASIL, 2019e, p. 2, grifo nosso). O mesmo princípio serve para aquele que "impedir acesso ou recusar hospedagem em hotel, pensão, estalagem, ou qualquer estabelecimento similar"; e a mesma lógica se estende a: restaurantes, bares, salões, barbearias, abarcando até a convivência familiar ou social, "não sendo considerada criminosa a conduta fundada na liberdade de consciência e de crença” (BRAsIL, 2019e, p. 2), ou "praticar, induzir ou incitar discriminação" desde que tais práticas estejam assentadas na mesma "liberdade de consciência e crença". Na justificativa, fica claro que o Estado não deve intervir na gestão privada dos espaços, uma vez que a gestão dos estabelecimentos é feita "em conformidade com a fé dos proprietários" (BRASIL, 2019e, p. 4). Para o proponente, existe uma regulação exacerbada e "já existem vários casos em que um discurso religioso - puro e simples - foi interpretado como criminoso" (Ibid.), como o fora o discurso do pastor da Geração Jesus Cristo, Tupirani da Hora Lopes, quando falou em pisar, massacrar e esmagar os judeus como vermes ${ }^{10}$.

Um contraditório, muito pontual, é então posto à mesa pelo PL 5120/13 (em proposição conjunta de Érika Kokay/PT e Jean Wyllys/PSOL), que diz que "da mesma maneira que o Estado não deve interferir na liberdade religiosa, as religiões

8 Ainda que em agosto de 2020 o Tribunal Superior Eleitoral tenha votado pela rejeição do Recurso Especial Eleitoral n⿳ 8285/2016, uma vez que inexiste a figura jurídica do "abuso de poder religioso". O caso concreto julgado foi o de uma vereadora da cidade de Luziânia (GO) que teria usado o templo no qual é pastora para fazer sua própria campanha eleitoral em 2016, segundo a representação do Ministério Público Estadual de Goiás.

9 Através do julgamento da Ação Direta de Inconstitucionalidade por Omissão (ADO) $n^{\circ} 26$, o Supremo Tribunal Federal (STF) equiparou os crimes de homofobia e transfobia aos de racismo em 12 de junho de 2019.

10 A decisão proferida pelo STF contrária ao Habeas Corpus no 146.303 , tentado por Tupirani, é mencionada por Otoni de Paula como exemplo da excessiva intervenção do Estado à liberdade religiosa. 
não devem interferir no direito civil”. Na maior parte das propostas, contudo, a reclamação é no sentido inverso, de que a liberdade religiosa deve imperar, por ser direito fundamental, mesmo quando, porventura, outros direitos igualmente fundamentais contra ela concorram:

a) PL 3407/20 (Enéias Reis/PSL): "acreditamos ser imperioso assegurar aos ministros do Evangelho [...] o direito de não celebrarem cerimônias de casamento homoafetivos" (BRASIL, 2020b, p. 2, grifo nosso);

b) PL 885/19 (Paulo Bergston/PTB): “a divulgação de ideias contrárias a um determinado comportamento ou crença, professada por um determinado grupo, religioso ou não, não constitui ilícito” (BRASIL, 2019d, p. 1, grifo nosso); ou

c) PL 2909/15 (Comissão de Legislação Participativa ${ }^{11}$ ): "qualquer ato de ingerência caracterizaria um evidente risco de se abrir um precedente neste sentido [de permitir a intervenção estatal em entidade religiosa], o que seria extremamente danoso para a convivência entre diferentes crenças e o relacionamento entre as denominações cristãs e as autoridades constituídas" (BRAsil, 2015, p. 171, grifo nosso); e ainda

d) PL 3368/19 (Cezinha de Madureira/PSD): que excetua as igrejas de terem que firmar Termos de Adesão para a realização de trabalhos voluntários.

Nesse sentido, chama a atenção a apreciação que recebeu o PL 2756/11, de Eros Biondini (PTB/PROS, evangelizador da Renovação Carismática Católica), e João Campos (MDB/REP). Os autores enxergam uma ofensiva do Estado contra a liberdade religiosa e acrescentam que "observa-se, nos últimos tempos, o crescimento do poder do Estado, violando as normas e convicções das entidades civis" (BRASIL, 2011a, p. 2). O PL conta com um único artigo que diz que "é livre de interferência do Poder Público a atividade sacerdotal, sendo assegurado aos clérigos o exercício dos atos litúrgicos em estrita conformidade com os respectivos ordenamentos religiosos" (BRAsIL, 2011a, p. 1, grifo nosso). Essa perspectiva é reforçada pelo relator Paulo Magalhães (PSD). Apesar de ter votado contra a juridicidade do PL, sua contrariedade se baseia no seguinte argumento:

11 Como a legislação brasileira suporta sugestões populares de leis, existe uma comissão parlamentar específica para tratar do encaminhamento dessas demandas. No caso em questão, a proposta foi encaminhada pela Associação Paranaense de Advogados Criminalistas e referendada pelo então presidente da Comissão, Fábio Ramalho (MDB). 
Considerando-se que o país se caracteriza por um pluralismo religioso, abrigando inúmeras religiões com práticas diversas, e algumas seitas, que utilizam em seus ritos animais, pessoas e até crianças, é de se esperar que o Poder Público possa intervir, a fim de afastar qualquer ameaça à ordem, à saúde e à segurança públicas. (BRASIL, 2012a, p. 2).

Ou seja, a intervenção deve ser sustentada não para garantir o pluralismo, mas justamente como resposta à existência fática deste. Analogamente, o PL 8062/17 (Pr. Eurico/PHS) visa proibir o sacrifício de animais em rituais religiosos, porque, com essa prática "interesses de determinados segmentos sobrepõe-se aos da coletividade" (Brasil, 2017b, p. 2). Além disso, "é imensurável o sofrimento que advém do constrangimento a que somos submetidos, encontrando os corpos em putrefação utilizados nas oferendas em locais públicos, tais como as ruas e praças de nossas cidades" (BrasiL, 2017, p. 3). Esta proposição está anexada ao PL 4331/12, do Pr. Marco Feliciano (PSC), em que ele argumenta: "Em consulta feita à Federação Espírita do Estado de São Paulo, nos foi informado que aquela entidade que congrega todos os Centros Espíritas daquele Estado (sic), não reconhece nenhum ritual que pratique sacrifício de animais" (BRASIL, 2012b, p. 2) ${ }^{12}$. Sentido similar tem a proposta de regulamentação do uso de "substâncias entorpecentes" em rituais religiosos (PL 6238/19, Celso Russomano/REP), defendendo que a ingerência do Estado em espaço litúrgico não é demasiada quando se trata da regulação de medicinas consideradas sagradas por povos indígenas (como a ayahuasca, a sananga, o rapé etc.).

Para finalizar esta seção e chegarmos às conclusões, insta observar que a liberdade religiosa tem também uma dimensão positiva. Nas proposições analisadas "liberdade religiosa" não é somente a não-intervenção do Poder Público nos atos litúrgicos: esta perspectiva é complementada pela ideia de que deveriam ser garantidos às organizações religiosas mecanismos específicos de interferência no Estado. É o caso da PEC no 99/2011, assinada por João Campos (PSDB) e coletivamente idealizada pela Frente Parlamentar Evangélica. A PEC modifica o art. $103^{\circ}$ da Constituição que dispõe, de maneira restrita, as instâncias que teriam legitimidade para proporem Ação Direta de Inconstitucionalidade (ADIn) ao STF, inserindo “as

12 Em 28 de março de 2018 o STF julgou o Recurso Extraordinário no 494601, para verificar a constitucionalidade da Lei Estadual $n^{0}$ 12.131/o4 do Rio Grande do Sul, que excetua a proibição de sacrifício animal em "cultos e liturgias de matriz africana". A maioria da corte entendeu que: "segundo a crença, somente quando a vida animal é extinta sem sofrimento se estabelece a comunicação entre os mundos sagrado e temporal”. 
associações religiosas de âmbito nacional" dentre as organizações que teriam essa prerrogativa. O princípio do artigo original já compreende instâncias que tenham alcance nacional, como as casas parlamentares, partido político com representação no Congresso e confederação sindical de âmbito nacional. Seguindo este entendimento, a PEC se preocupou em destacar que as associações religiosas que entrariam para o rol de entidades legitimadas deveriam ser "de âmbito nacional". Tais organizações teriam como propor ADIn à Lei $\mathrm{n}^{0}$ 12.131/o4-RS, por exemplo (vide nota $\mathrm{n}^{0}$ 10). Mas é claro, também, que nem todas as religiões contam com uma estrutura episcopal ou similar, como é o caso, uma vez mais, das religiões de matriz africana ou as indígenas, por exemplo. E o que está implícito no caput da minuta torna-se patente na justificação que diz:

O movimento evangélico cresce no Brasil, portanto, associado ao sentimento de liberdade cívica que vem à luz com a República, onde a Constituição como norma fundamental assume grande significado político, tornando-se, sobretudo, instrumento de garantia individual e de limitação de poder do Estado, e como tal, passa a iluminar o sistema jurídico nacional. Neste contexto, não há como não se reconhecer o mérito dos Evangélicos brasileiros em coadjuvar na consolidação de princípios no cerne da Constituição, como garantidores da liberdade de culto e de religião (BRASIL, 2011b, p. 3).

O mesmo João Campos propõe a colaboração de interesse público entre o Estado e organizações religiosas através do PL 2386/07. Sabemos que já existe previsão de colaboração do Estado com Organizações da Sociedade Civil de Interesse Público (OSCIP) (Lei nº 9790/99) para finalidades de interesse público - ou seja, as organizações religiosas já têm o direito de constituir uma OSCIP, desde que o objeto do contrato não seja proselitismo. Ainda assim, o PL, bem como os relatores que o apreciaram, compreende que deve haver um instrumento legal que especifique a colaboração com organizações religiosas. É certo que o inciso I do art. $19^{\circ}$ da Constituição - o mesmo inciso que veda os entes estatais de "embaraçar" o funcionamento de cultos e igrejas -, veda também a aliança com os mesmos cultos e igrejas, ressalvada a colaboração de interesse público. Contudo, é justamente no sentido de abranger tais colaborações que a lei das OSCIPs vigora, verificável por qualquer pesquisa simples ao sítio do Ministério da Justiça, onde consta uma série de contratos vigentes entre organizações geridas por fundações religiosas e o Poder Público. 
Com tais informações, apresentadas de maneira bastante sintética, avancemos às conclusões, que servirão como esforço analítico complementar às pontuações que já vimos tecendo ao longo da exposição.

\section{CONCLUSÕES}

Conforme a acepção assumida na seção teórica, o conceito de secularização nos remete, por princípio, a uma separação entre a estrutura jurídico-política de quaisquer organizações ou determinações de origem religiosa. Também reconhecemos que a laicidade deve comportar dois aspectos: a) que o Estado não arbitre ou funde suas normas (normas estas que ao cabo subsidiam as decisões jurídicas) segundo orientações de uma religião específica, respeitando o princípio da equidistância ou da neutralidade; e que b) ele propicie espaços para a participação da pluralidade de religiões na conformação da esfera pública, correspondendo à laicidade positiva ou laicidade inclusiva.

O movimento de separação é normalmente compreendido como uma emancipação da sociedade com relação à religião (FoERster, 2007, p. 204) através da consolidação de um “moderno Estado laico como domínio da lei” (PIERUCCI, 1998, p. s.p.). Contudo, devemos atentar para a mobilização existente para a realização dessa mesma separação em perspectiva inversa. Ou seja, há um esforço para a emancipação da religião com relação ao Estado, conforme já havia atentado Camurça (2017, p. 883). Essa é a posição de boa parte dos casos ora apresentados, que enxergam como demasiada a interferência do Poder Público sobre a res religiosa, visão materializada no PLs acerca de isenção de emolumentos cartoriais, vedação de tributação sobre rendas e serviços religiosos ou mesmo os projetos que versam sobre a exclusão de crime de injúria, difamação ou intolerância para ministros de culto. Porém, ao mesmo tempo, autores identificados com o espectro cristão reclamam a ação do Estado em rituais que envolvem sacrifício animal ou a utilização de medicinas sagradas para certos povos indígenas; esforço paralelo e na mesma direção ao da criminalização do sacrilégio e da "cristofobia”. Estes dois exemplos mostram que o escopo de atuação do Estado é axiologicamente filtrado segundo a perspectiva cristã, compreendendo uma especiação do princípio da liberdade religiosa previsto no art. 19 da Constituição: a liberdade das religiões torna-se liberdade da religião. Ora essa defesa é feita de forma explícita, como propostas que fundamentam suas justificações em nome dos valores cristãos enquanto formadores da sociedade brasileira (e.g. a PEC 99/11 e o PL 4152/19), ou mesmo as que justificam sua posição abertamente cristã pelo fato de os cristãos serem a maioria numérica da sociedade. Outras são menos diretas, e a especiação 
do princípio e a "separação seletiva" somente são percebidas quando feita uma análise mais detida do próprio texto da proposição. É o caso da mesma PEC 99/11 que, já em sua ementa, menciona as "organizações religiosas de âmbito nacional", mas também do PL 3368/19, que desobriga igrejas a elaborarem Termo de Adesão para realização de serviços voluntários.

O mesmo vale para a questão da laicidade, compreendida pela neutralidade arbitral do Estado e pela participação das diversas vozes religiosas na consolidação da esfera pública. Esse último quesito, recorrentemente lembrado pela literatura contemporânea, é uma resposta àquela noção "laicista" combativa, jacobinista e datada, prosélita da exclusão de toda manifestação religiosa de qualquer espaço público. Porém, a regulamentação da participação das religiões nos diversos debates públicos - como na construção da base curricular, na adequação de políticas sanitárias ou mesmo na formulação de políticas de promoção da diversidade - parece secundarizada pelo parlamento brasileiro, pois percebe-se a predominância de propostas que apontam para a expansão de valores especificamente cristãos ao invés de apontarem para a sua pluralidade. São expressões de valores filiados a uma concepção específica de transcendência que se usa do formalismo para ganhar validade geral. Sintomático é o PL 701/19 (Otoni de Paula/PSC) que altera a Lei de Diretrizes Básicas da Educação, onde se lê que

\footnotetext{
"é impossível que, diante das liberdades de consciência e crença [...] o Estado oferte apenas conteúdo interconfessional e não proselitista. [...] Do contrário teríamos o Estado criando para si uma religião - a 'religião interconfessional' -, mas isso não é possível diante da laicidade” (BRAsıL, 2019f, p. 7).
}

Também é o caso do PLP 219/20 que modifica a legislação eleitoral, permitindo campanhas políticas dentro de igrejas, já que "as ideias religiosas têm legitimidade para participar do debate político" (BRASIL 2020a, p. 3); ou ainda os PLs n ${ }^{0}$ 1/2019 e 4322/19 que propõem que a Bíblia se torne patrimônio imaterial do Brasil; ou as que propõem a instituição de dias de oração ou similares a nível nacional ou ainda o estudo bíblico para os ensinos fundamental e médio.

Se assumirmos o conceito de laicidade derivado de Blancarte e Fábio Leite - e aqui esperamos que o conceito tenha a merecida independência com relação ao norte constitucional -, vemos que os valores correntes nas últimas legislaturas tendem para especiação do princípio e, consequentemente, pela contraposição empírica ao próprio conceito. Pois se a laicidade, conforme Blancarte nos atualiza, reverteu-se historicamente em ferramenta para que as minorias pudessem 
adquirir espaços de legitimidade (BLANCARTE et al, 2018), argumentos no sentido da "maioria cristã" ou da valoração positiva do cristianismo na formação da sociedade brasileira vão de encontro a qualquer noção de pluralismo. Mesmo a "equidistância" sugerida por Leite é contestada, uma vez que a "blasfêmia" e a "cristofobia" ganhariam lentes privilegiadas da legislação, sem abranger os sub-reptícios atos de intolerância praticados contra as minorias, sociológicas e/ou numéricas. Leite atenta para o fato de que:

[...] por trás da neutralidade com a qual se apresentam as decisões políticas tomadas por órgãos representativos do Estado, existem uma moral e uma cultura dominante com a qual eventualmente contrastam-se as culturas minoritárias, gerando um conflito que é usualmente resolvido em favor da cultura dominante, a partir da ideia moderna de supremacia do poder político (LeITE, 2014, p. 111).

Portanto, o instituto da liberdade religiosa - norteador do princípio da laicidade - visa, ao menos imediatamente, à proteção de direitos das minorias, uma vez que ficaria esvaziado de propósito se evocado apenas para a manutenção ou alargamento de uma hegemonia.

A estratégia escolhida para o presente trabalho foi rastrear os valores que embasam as propostas legislativas que concernem à liberdade religiosa. Tais valores fundamentam normas de repercussão geral que, ao fim e ao cabo, arregimentam as posturas em sociedade. Parece-nos promissor que trabalhos semelhantes sejam desenvolvidos buscando a transversalidade desses valores com outras decisões políticas que não digam respeito diretamente aos interesses das organizações religiosas. É importante fazer uma cartografia desses valores e sua relação com temas que atravessam toda a sociedade, como, por exemplo, seu peso em decisões que envolvem as liberdades civis. Cremos que a compreensão das relações entre religião, esfera pública e Estado é fundamental para tanto, e nisso reside nossa contribuição.

\section{REFERÊNCIAS BIBLIOGRÁFICAS}

ANDRADE, Susana. Entre la religion y la política. Montevideo: La Republica, 2009.

BAUbÉRot, Jean. Libertà religiosa e laicità in Francia. Lessico di etica pubblica, v. 2, n. 2, p. 59-71, 2011.

. La representation de la laïcité comme 'exception française'. Cosmopolitiques, n. 16, p. 119-134, 2007. 
Blancarte, Roberto; et al. As encruzilhadas da laicidade na América Latina. Religião e Sociedade, v. 38, n. 2: 9-21, 2018.

Blancarte, Roberto. ¿Por qué la religion "regresó" a la esfera pública en un mundos ecularizado?. Estudios Sociologicos, v. XXXIII, n. 99, p. 659-673, 2015.

.América Latina: entre pluriconfesionalidad y laicidad". Civitas, Porto Alegre, v. 11, n. 2, p. 182-206, 2011.

.Laicidad: la construcción de un concepto de validez universal”. In: DACostA, Néstor (org.) Laicidad en America Latina y Europa: repensando lo religioso entre lo público e lo privado en el siglo XXI. Montevideo: CLAEH, 2006, p. 32-51.

Bossio, María Pilar García. La laicidad problematizada: su uso para pensar organismos governamentales. Religião e Sociedade, v. 38, n. 2, p. 148-173, 2018.

BRASIL. Comissão de Constituição e Justiça e de Cidadania. Projeto de Lei No 6.314, de 2005. Brasília, Câmara dos Deputados, 2006. Disponível em: <https://www.camara. leg.br/proposicoesWeb/prop_mostrarintegra;jsessionid=nodeonntevvd6p75i8j9jv9j jefoi5397513.nodeo?codteor $=379511 \&$ filename $=$ Tramitacao $-\mathrm{PL}+6314 / 2005>$ Acesso em: 23/05/2021.

BRASIL. Projeto de Lei No 2756, de 2011. Brasília, Câmara dos Deputados, 2011a. Disponível em: <https://www.camara.leg.br/proposicoesWeb/prop_mostrarintegra?codteor=9 42229\&filename=Tramitacao-PL+2756/2011>Acesso em: 23/05/2021.

BRASIL. Projeto de Emenda Constitucional No 99, de 2011. Brasília, Câmara dos Deputados, 2011b. Disponível em: <https://www.camara.leg.br/proposicoesWeb/prop_mostrarin tegra?codteor $=931483 \&$ filename $=$ Tramitacao-PEC+99/2011>Acesso em: 23/05/2021.

BRASIL. Comissão de Constituição e Justiça e de Cidadania. Projeto de Lei $N^{\circ}$ 2756, de 2011. Brasília, Câmara dos Deputados, 2012b. Disponível em: <https://www.camara. leg.br/proposicoesWeb/prop_mostrarintegra?codteor=1000708\&filename=Tramit acao-PL+2756/2011>Acesso em: 23/05/2021.

BRASIL. Projeto de Lei No 4331, de 2012. Brasília, Câmara dos Deputados, 2012b. Disponível em: <https://www.camara.leg.br/proposicoesWeb/prop_mostrarintegra?codteor=1 020499\&filename=Tramitacao-PL+4331/2012>Acesso em: 23/05/2021.

BRASIL. Projeto de Lei No 5120, de 2013. Brasília, Câmara dos Deputados, 2012c. Disponível em: <https://www.camara.leg.br/proposicoesWeb/fichadetramitacao?i dProposicao=567021>Acesso em: 23/05/2021.

Brasil. Comissão de Constituição e Justiça e de Cidadania. Projeto de Lei No 6.314, de 2013. Brasília, Câmara dos Deputados, 2013. Disponível em: <https://www.camara. leg.br/proposicoesWeb/prop_mostrarintegra;jsessionid=nodeonntevvd6p75i8j9j v9jjefoi5397513.nodeo?codteor=1088463\&filename=Tramitacao-PL+6314/2005> Acesso em: 23/05/2021. 
BRASIL. Comissão de Constituição e Justiça e de Cidadania. Projeto de Lei No 1804, de 2015. Brasília, Câmara dos Deputados, 2015a. Disponível em: <https://www.camara. leg.br/proposicoesWeb/prop_mostrarintegra?codteor=1367422\&filename=Tramit acao-PL+1804/2015>Acesso em: 23/05/2021.

Brasil. Projeto de Lei No 2909, de 2015. Brasília, Câmara dos Deputados, 2015b. Disponível em: <http://imagem.camara.gov.br/Imagem/d/pdf/DCDo020150925001630000. PDF\#page=170 $>$ Acesso em: 23/05/2021.

BRASIL. Projeto de Lei No 8854, de 2017. Brasília, Câmara dos Deputados, 2017a. Disponível em: <https://www.camara.leg.br/proposicoesWeb/prop_mostrarintegra?codteor=1 610251\&filename=Tramitacao-PL+8854/2017>Acesso em: 23/05/2021.

Brasil. Projeto de Lei No 8062, de 2017. Brasília, Câmara dos Deputados, 2017b. Disponível em: <https://www.camara.leg.br/proposicoesWeb/prop_mostrarintegra?codteor=1 578002\&filename=Tramitacao-PL+8062/2017>Acesso em: 23/05/2021.

Brasil. Projeto de Lei $\mathrm{N}^{\circ}$ 2544, de 2019. Brasília, Câmara dos Deputados, 2019a. Disponível em: <https://www.camara.leg.br/proposicoesWeb/prop_ mostrarintegra? codteor $=1737645 \&$ filename $=$ Tramitacao $-\mathrm{PL}+2544 / 2019>$ Acesso em: 23/05/2021.

Brasil. Projeto de Lei No 4152, de 2019. Brasília, Câmara dos Deputados, 2019b. Disponível em: <https://www.camara.leg.br/proposicoesWeb/prop_mostrarintegra?codteor=1 781213\&filename=Tramitacao-PL+4152/2019>Acesso em: 23/05/2021.

BRASIL. Projeto de Lei No 5200, de 2019. Brasília, Câmara dos Deputados, 2019c. Disponível em: <https://www.camara.leg.br/proposicoesWeb/prop_mostrarintegra?codteor=1 811434\&filename=Tramitacao-PL+5200/2019>Acesso em: 23/05/2021.

BRASIL. Projeto de Lei No 885, de 2019. Brasília, Câmara dos Deputados, 2019d. Disponível em: <https://www.camara.leg.br/proposicoesWeb/prop_mostrarintegra?codteor=1 71210o\&filename $=$ Tramitacao-PL+885/2019>Acesso em: 23/05/2021.

BRASIL. Projeto de Lei No 4949, de 2019. Brasília, Câmara dos Deputados, 2019e. Disponível em: <https://www.camara.leg.br/proposicoesWeb/prop_mostrarintegra?codteor=1 805142\&filename=Tramitacao-PL+4949/2019>Acesso em: 23/05/2021.

BRASIL. Projeto de Lei No 701, de 2019. Brasília, Câmara dos Deputados, 2019f. Disponível em: <https://www.camara.leg.br/proposicoesWeb/prop_mostrarintegra?codteor=1 710040\&filename $=$ Tramitacao-PL+701/2019>Acesso em: 23/05/2021.

Brasil. Projeto de Lei Complementar No 219, de 2020. Brasília, Câmara dos Deputados, 2020a. Disponível em: <https://www.camara.leg.br/proposicoesWeb/prop_most rarintegra? codteor $=1924212 \&$ filename $=$ Tramitacao $-\mathrm{PLP}+219 / 2020>$ Acesso em: 23/05/2021. 
BRASIL. Projeto de Lei $\mathrm{N}^{0}$ 3407, de 2020. Brasília, Câmara dos Deputados, 2020b. Disponível em:<https://www.camara.leg.br/proposicoesWeb/prop_mostrarintegra ?codteor=1905429\&filename=Tramitacao-PL+3407/2020 $>$ Acesso em: 23/05/2021. CAETANO, Gerardo. Laicidad, ciudadanía y política en el Uruguay contemporáneo: matrices y revisions de una culturalaicista. Revista Cultura y Religión, vol. VII, n. 1, p. 116-139, 2013.

"Laicismo y política en el Uruguay contemporáneo: una mirada desde la historia”. In: DACosta, Néstor (org.) Laicidad en America Latina y Europa: repensando lo religioso entre lo público e lo privado en el siglo XXI. Montevideo: CLAEH, 2006, p. 92-123.

CAmurÇA, Marcelo Ayres. "A questão da laicidade no Brasil: mosaico de configurações e arena de controvérsias". Horizonte, Belo Horizonte, v. 15, n. 47, p. 855-886, 2017.

CASAnova, José. Public religion in the modern world. Chicago: The University of Chicago Press, 1994.

DACosta, Néstor. "Laicidad, secularización y pluralismo. Reflexiones desde el caso uruguayo". In: CAPDEVIELLE, Pauline (coord.) Nuevos retos y perspectivas de la laicidad. Ciudad del Mexico: Instituto de Investigaciones Juridicas, 2017, p. 73-88.

El fenómeno de la laicidad como elemento identitario: el caso uruguayo. Civitas, v. 11, n. 2: 207-220, 2011.

Dobbelaere, Karel. Secularization: an analysis at three levels. Brussels: Peter Lang, 2002. FoERster, Norbert Hans Christoph. "Pentecostalismo clássico e secularização". Estudos de Religiao (IMS), v. 32, p. 196-214, 2007.

VALLEJO, Iván Garzón. Argumentos laicos para uma revisión de la secularización. Prudentia Iuris, n. 66, v. 67. p. 226-246, 2009.

Giumbelli, Emerson. Regulação do religioso: discussões conceituais e panorama da situação em quatro países da América Latina. Ciências Sociais e Religião, v. 18, n. 25, p. 14-37, 2016.

Giumbelli, Emerson; Scola, Jorge. "Definindo a liberdade religiosa: projetos acerca do estatuto de instituições religiosas no Congresso Nacional brasileiro”. In: ARAúJo, Melvina; Cunha, Christina (orgs.) Religião e Conflito. Curitiba: Prismas, 2016: 25-44. Gunn, Jeremy. Religious freedom and laicité: a comparison of the United States and France. BYU Law Review, n. 419, p. 419-506, 2004.

LEITE, Fábio Carvalho. Estado e religião: a liberdade religiosa no Brasil. Curitiba: Juruá, 2014 .

MARIANo, Ricardo. Laicidade à brasileira: católicos, pentecostais e laicos em disputa na esfera pública. Civitas, v. 11, p. 238-258, 2011. 
Oro, Ari Pedro. A laicïté em questão: um comentário a um texto de Luca Diotalevvi. Debates no NER, v. 16, n. 27. p. 51-62, 2015.

PIERucci, Antônio Flávio. O crescimento da Liberdade religiosa e o declínio da religião tradicional: a propósito do censo de 2010. ANUAC, v. 1, n. 2, p. 87-96, 2012. Secularização em Max Weber: da Contemporânea Serventia de Voltarmos a Acessar aquele Velho Sentido. Revista Brasileira de Ciências Sociais, v. 13, n. 37, s/p, 1998.

StEPAN, Alfred. The multiple secularisms of modern democratic and non-democratic regimes. APSA 2010 Annual Meeting Paper, s/p, 2011.

TAHIRLI, Taleh. Secularization in a society with a strong religious ideology: the case of Turkey. Dissertação(Department of Management and Economics.). Linköping, Linköping University Press, 2005.

Tschannen, Olivier. Les théories de la sécularisation. Genebra: Librarie Droz, 1992. 